\title{
Global air-sea surface carbon-dioxide transfer velocity and flux estimated using ERS-2 data and a new parametric formula
}

\author{
YU Tan ${ }^{1,2,3,4,5}$, HE Yijun ${ }^{4 *}$, ZHA Guozhen ${ }^{1,2,3}$, SONG Jinbao ${ }^{1,3}$, LIU Guoqiang ${ }^{1,2,3}$, GUO Jie ${ }^{6,7}$ \\ ${ }^{1}$ Institute of Oceanology, Chinese Academy of Sciences, Qingdao 266071, China \\ ${ }^{2}$ University of Chinese Academy of Sciences, Chinese Academy of Sciences, Beijing 100049, China \\ ${ }^{3}$ Key Laboratory of Chinese Academy of Sciences for Ocean Circulation and Waves (KLOCAW), \\ Institute of Oceanology, Chinese Academy of Sciences, Qingdao 266071, China \\ ${ }^{4}$ School of Marine Sciences, Nanjing University of Information Science and Technology, Nanjing 210044, \\ China \\ ${ }^{5}$ College of Marine Sciences, Shanghai Ocean University, Shanghai 201306, China \\ ${ }^{6}$ Key Laboratory of Chinese Academy of Sciences for Coastal Zone Environmental Processes, \\ Yantai Institute of Coastal Zone Research, Chinese Academy of Sciences, Yantai 264003, China \\ ${ }^{7}$ Key Laboratory of Shandong Province for Coastal Zone Environmental Processes, Yantai Institute of \\ Coastal Zone Research, Chinese Academy of Sciences, Yantai 264003, China
}

Received 4 June 2012; accepted 28 September 2012

(CThe Chinese Society of Oceanography and Springer-Verlag Berlin Heidelberg 2013

\begin{abstract}
Using data from the European remote sensing scatterometer (ERS-2) from July 1997 to August 1998, global distributions of the air-sea $\mathrm{CO}_{2}$ transfer velocity and flux are retrieved. A new model of the air-sea $\mathrm{CO}_{2}$ transfer velocity with surface wind speed and wave steepness is proposed. The wave steepness $(\delta)$ is retrieved using a neural network (NN) model from ERS-2 scatterometer data, while the wind speed is directly derived by the ERS-2 scatterometer. The new model agrees well with the formulations based on the wind speed and the variation in the wind speed dependent relationships presented in many previous studies can be explained by this proposed relation with variation in wave steepness effect. Seasonally global maps of gas transfer velocity and flux are shown on the basis of the new model and the seasonal variations of the transfer velocity and flux during the 1 a period. The global mean gas transfer velocity is $30 \mathrm{~cm} / \mathrm{h}$ after area-weighting and Schmidt number correction and its accuracy remains calculation with in situ data. The highest transfer velocity occurs around $60^{\circ} \mathrm{N}$ and $60^{\circ} \mathrm{S}$, while the lowest on the equator. The total air to sea $\mathrm{CO}_{2}$ flux (calculated by carbon) in that year is $1.77 \mathrm{Pg}$. The strongest source of $\mathrm{CO}_{2}$ is in the equatorial east Pacific Ocean, while the strongest sink is in the $68^{\circ} \mathrm{N}$. Full exploration of the uncertainty of this estimate awaits further data. An effectual method is provided to calculate the effect of waves on the determination of air-sea $\mathrm{CO}_{2}$ transfer velocity and fluxes with ERS-2 scatterometer data.
\end{abstract}

Key words: gas transfer velocity, carbon dioxide flux, wave steepness, European remote sensing scatterometer

Citation: Yu Tan, He Yijun, Zha Guozhen, Song Jinbao, Liu Guoqiang, Guo Jie. 2013. Global air-sea surface carbon-dioxide transfer velocity and flux estimated using ERS-2 data and a new parametric formula. Acta Oceanologica Sinica, 32(7): 78-87, doi: 10.1007/s13131-013-0334-0

\section{Introduction}

It is widely believed that $\mathrm{CO}_{2}$ is one of the most important drivers of global climate change. At present, considerable quantities of anthropogenic $\mathrm{CO}_{2}$ are released into the atmosphere as a result of human activities such as fossil fuel burning and deforestation (Keeling et al., 1995; Denman et al., 2007). Approximately $60 \%$ of total $\mathrm{CO}_{2}$ emissions stay in the atmosphere and the rest are assumed to sequester into the oceans (about $1 / 3$ of the total of the long-term potential) (Sarmiento et al., 2000; Sabine et al., 2004).

Evaluating the air-sea flux of $\mathrm{CO}_{2}$ is essential to understand the air-sea exchange of $\mathrm{CO}_{2}$. There are two approaches to measuring $\mathrm{CO}_{2}$ fluxes between the oceans and the atmosphere. One is direct measurement of $\mathrm{CO}_{2}$ fluxes using new fast-response detectors of the $\mathrm{CO}_{2}$ concentration, e.g., eddy co- variance technology (Fairaill et al., 2000; McGillis et al., 2001a,b; Miller et al., 2010; Prytherch et al., 2010). Accurate and continuous in situ data can be obtained by this method. However, it is not possible to obtain global data by this methodology for its enormous cost. The second measures $\mathrm{CO}_{2}$ fluxes using remote sensing techniques. This is based on famous Bulk formula theory (Frew et al., 2007; Glover et al., 2007; Bogucki et al., 2010).

The bulk formula is the products of the difference of the partial pressure of $\mathrm{CO}_{2}$ between air and seawater and the $\mathrm{CO}_{2}$ transfer velocity which depends on the air-sea boundary-layer process. It is described as (Frankignoulle, 1988):

$$
F=k L \Delta p_{\mathrm{CO}_{2}}
$$

where $F$ is the flux of $\mathrm{CO}_{2}$ in $\mathrm{mmol} /\left(\mathrm{m}^{2} \cdot \mathrm{d}\right) ; k$ is the air-sea sur-

Foundation item: Public Science and Technology Research Funds Projects of Ocean under contract No. 200905012; a project funded by the Priority Academic Program Development of Jiangsu Higher Education Institutions (PAPD) of China.

*Corresponding author, E-mail: yjhe@nuist.edu.cn 
face transfer velocity $(\mathrm{cm} / \mathrm{h}) ; L$ is the solubility of $\mathrm{CO}_{2}$ in $\mathrm{mmol} / \mathrm{LPa}$; and $\Delta p_{\mathrm{CO}_{2}}$ is the air-sea partial pressure difference in $\mu \mathrm{Pa}$.

The gas transfer velocity is a key parameter that describes the kinetics of the air-sea boundary layer, and is vital to the estimation of air-sea $\mathrm{CO}_{2}$ budgets. Many former studies give the gas transfer velocity as a function of wind speed (Liss and Merlivat, 1986; Wanninkhof, 1992; Jacobs et al., 1999; Nightingale et al., 2000; Kuss et al., 2004; Sweeney et al., 2007). This approach was used because wind is the primary forcing factor of the air-sea transfer, and wind-speed data are easy to obtain from routine observations or remote sensing.

However, wind is not the only factor driving the gas exchange, in addition to wind, the effect of ocean waves should also be considered in the parameterization of the gas transfer velocities (Wanninkhof, 1992; Zhao et al., 2003; Perrie et al., 2004; Woolf, 2005; Wanninkhof et al., 2009). Jähne et al. (1987) suggest that the gas transfer velocity is correlated linearly with the total mean square slope. Subsequent laboratory studies have found that the gas transfer velocity shows a reasonable correlation with the mean square slope of short wind waves, but correlates poorly with that of long waves (Bock et al., 1999). Frew et al. (2004) studied the relationship between the air-sea gas transfer velocity and the wind stress, the small-scale waves, and the surface films, and developed the relationships using the NSF-CooP coastal air-sea chemical fluxes study data. They presented a new approach to the estimation of global velocity fields of air-sea gas transfer using dual-frequency altimeter backscatter (Frew et al., 2007). The algorithm was constructed using empirical observations of the dependence of gas transfer velocity on the mean square slope, coupled with the estimation of mean square slope from altimeter backscatter and a geometric optics scattering model. Glover et al. (2007) estimated also a long-term global time series air-sea gas transfer velocity from the Jason-1 and TOPEX altimeters. Recently, Bogucki et al. (2010) developed a novel approach to calculating air-sea $\mathrm{CO}_{2}$ transfer velocities using the new satellite scatterometer (QuikSCAT), in which the gas transfer velocity is estimated from QuikSCAT backscattering directly, not via wind speed. They considered the mean square slope to link the gas transfer velocity and QuikSCAT backscattering. In realistic ocean, the wave age and the wave steepness are parameters that describe the state of the wave. Zhao and Xie (2010) have discussed the effect of wave age on the gas transfer velocity. Many former research works can be a specific case by choosing a certain value of the wave age.

Wave conditions may well be similar in the sense that the significant wave height and period are equal, but they may still be very different in detail: a mixed sea state of wind sea (short, irregular, locally generated waves) and swell (long, smooth waves, generated in a distant storm) may have the same significant wave height and period as a slightly higher wind sea without swell. To distinguish such conditions, more parameter$\mathrm{s}$ are needed, for instance, a significant wave height and period for wind sea and swell separately (Holthuijsen, 2007). Hence, only one parameter of the significant wave height or period is not enough to describe the real sea state while the steepness contains both. Therefore, the wave steepness is better than the significant wave height to describe the real sea state. And the wind wave has higher wave steepness while the swell has lower one. Hence, the wind wave has lower transfer velocity while the swell has higher one under the same wind speed. Furthermore, while it is difficult to obtain accurate wave ages from the remote sensing data, the wave steepness can be obtained easily from the European Remote Sensing Satellite 2 (ERS-2) scatterometer data using a neural network (NN) model. We have also calculated the wave age using the same method as the wave steepness. Their results are not as good as those of the wave steepness. The correlation coefficient $(r)$ between the buoy calculated wave age and that retrieved from ERS-2 data was much smaller than that of wave steepness and they are more scattered. In addition, from Eq. (2) and Eq. (3) we can see that the wave age depends on the wind speed and the wave phase speed while the wave steepness only depends on the wave, and it is better for the wave steepness to describe the wave state.

In this study, the wave steepness is introduced to estimate the gas transfer velocity. This is a new approach to evaluation of the air-sea flux of $\mathrm{CO}_{2}$ using a remote sensing technique and it is consistent with many previous formulations of the gas transfer velocity under the given wave steepness conditions. We also provide an upper limit for the gas transfer velocity of the fully developed wave field and estimate the global air-sea $\mathrm{CO}_{2}$ transfer velocity and flux.

\section{Methods}

\subsection{Formula for gas transfer velocity}

We first define the wave age and steepness, respectively, as (Holthuijsen, 2007)

$$
\begin{aligned}
\beta & =C_{\mathrm{p}} / U_{10}=\left(g / \omega_{\mathrm{p}}\right) / U_{10}=g /\left(\omega_{\mathrm{p}} U_{10}\right), \\
\delta & =H_{\mathrm{s}} / L_{\mathrm{p}}=H_{\mathrm{s}} k_{\mathrm{p}} / 2 \pi=H_{\mathrm{s}}\left(\omega_{\mathrm{p}}^{2} / g\right) / 2 \pi \\
& =H_{\mathrm{s}} \omega_{\mathrm{p}}^{2} /(2 \pi g),
\end{aligned}
$$

where $C_{\mathrm{p}}$ is the phase speed $(\mathrm{m} / \mathrm{s})$ at the peak frequency of the wave spectrum; $U_{10}$ is the wind speed $(\mathrm{m} / \mathrm{s})$ at $10 \mathrm{~m}$ height above the sea surface under neutral stratification conditions; $g$ is the gravitational acceleration, $g=9.8 \mathrm{~m} / \mathrm{s}^{2} ; \omega_{\mathrm{p}}$ is the peak radian frequency $\left(\mathrm{s}^{-1}\right)$ of the wind wave spectrum; $H_{\mathrm{s}}$ is the significant wave height (m) (SWH) of wind waves; $L_{\mathrm{p}}$ is the wave length (m) at the peak frequency of the wave spectrum; and $k_{\mathrm{p}}$ is the wave number $\left(\mathrm{m}^{-1}\right)$ at the peak frequency of the wave spectrum.

Based on this, we can show

$$
2 \pi \delta \beta^{2}=2 \pi\left[H_{\mathrm{s}} \omega_{\mathrm{p}}^{2} /(2 \pi g)\right]\left[g /\left(\omega_{\mathrm{p}} U_{10}\right)\right]^{2}=g H_{\mathrm{s}} / U_{10}^{2} .
$$

Zhao and Xie (2010) proposed a formula for the gas transfer velocity as a function of the wind speed and the significant wave height:

$$
k_{660}=6.81\left(U_{10} H_{\mathrm{s}}\right)^{0.63},
$$

where $k_{660}$ is the air-sea surface transfer velocity $(\mathrm{cm} / \mathrm{h})$ normalized to a Schmidt number $S c$ of 660 .

Now, we can further show

$$
\begin{aligned}
k & =6.81\left(U_{10} H_{\mathrm{s}}\right)^{0.63}=6.81\left[\left(U_{10}^{3} / g\right)\left(g H_{\mathrm{s}} / U_{10}^{2}\right)\right]^{0.63} \\
& =6.81\left[\left(U_{10}^{3} / g\right) 2 \pi \delta \beta^{2}\right]^{0.63} .
\end{aligned}
$$

This shows that the gas transfer velocity is a function of the wind speed and a factor combining the wave steepness and the wave age, $\delta \beta^{2}$.

Furthermore, the relationship between the wave age $\beta$ and the wave steepness $\delta$ is proposed by Toba (1972) as

$$
\delta=0.031 \beta^{-1 / 2} .
$$


Substituting Eq. (7) into Eq. (6), the gas transfer velocity can be parameterized by the wind speed and the wind steepness as

$$
k=8.12 \times 10^{-4}\left(U_{10} / \delta\right)^{1.89} .
$$

Substituting Eq. (7) into Eq. (4), the relationship between the wave steepness and the significant wave height can be show as

$$
\delta=0.0084\left(H_{\mathrm{s}} / U_{10}^{2}\right)^{-\frac{1}{3}}
$$

Because it is assumed that the $\mathrm{SWH}$ cannot be greater than that of a fully developed wave field that is specified by the wind speed alone, and independent of fetch (Zhao and Xie, 2010), following Carter (1982), the maximum of SWH, $H_{\text {sm }}$, is taken as

$$
H_{\mathrm{sm}}=0.025 U_{10}^{2} \text {. }
$$

Substituting Eq. (10) into Eq. (9), the low limit of the wave steepness can be shown as $\delta_{\min }$. At the same time, the high limit of the wave steepness is $\delta_{\max }=1 / 15$ (Holthuijsen, 2007). So the valid range of the wave steepness is

$$
0.029 \leqslant \delta \leqslant 1 / 15 \text {. }
$$

\subsection{Data and the NN model}

To obtain the gas transfer velocity, a well-calibrated $10 \mathrm{~m}$ neutral wind is required. Portabella and Stoffelen (2009) have derived a statistical conversion method by adding $0.7 \mathrm{~m} / \mathrm{s}$ to the ERS- 2 wind speed to obtain the scatterometer $10 \mathrm{~m}$ neutral winds . Furthermore, although air stability has a considerable effect on the wind speed above the ocean surface, and thus on the accuracy of , the scatterometer winds are statistically as close to real wind as to neutral wind (Portabella and Stoffelen, 2007).

$U_{10}$ and the other ERS-2 WNF products $[\theta, \cos (\phi-\varphi)$ and NRCS] are used to retrieve the wave steepness using the NN model (Liu et al., 2011), where $\theta$ is the incidence angle of ERS-2, $\phi$ is the azimuth angle of ERS-2, and $\varphi$ is the wind direction of ERS-2. All of these angles are in degrees. The NRCS is the normalized radar cross-section in $\mathrm{dB}$. The ERS-2 WNF products are from CERSAT from 15 July 1997 to 2 August 1998. Sea ice and land data were removed. The training and validation data of the $\mathrm{NN}$ are derived from the matchups of ERS-2 observations and buoy measurements. The buoy data were taken from the National Data Buoy Center (NDBC). NDBC buoys collect wave data hourly, for each ERS-2 scatterometer data point, the two buoy data points before and after the ERS-2 scatterometer time are selected for comparison. A total of 10485 ERS-2 scatterometer observations, collocated with the NDBC buoy data were used. The distribution of the buoys is shown in Fig.1. These buoys

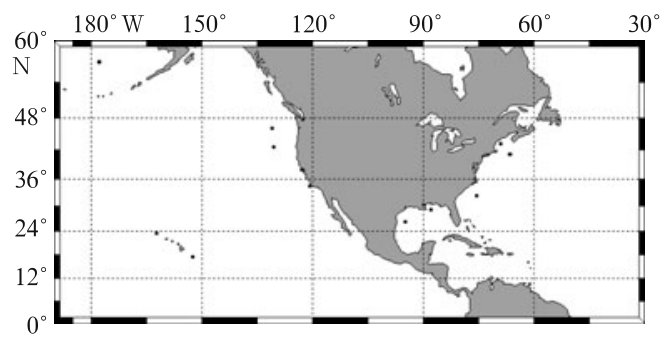

Fig.1. Distribution of buoys in the north Pacific and North Atlantic Ocean (squares). have deep-water locations with a minimum depth of $88.4 \mathrm{~m}$. Of the total data, 8285 data were used to train the $\mathrm{NN}$ and the remainder to verify the results.

The input data of the NN model include the incidence angle $\theta, \cos (\phi-\varphi)$, the NRCS, and the wind speed $U_{10}$. Output data $\delta$ is computed from the wave steepness equation below (Holthuijsen, 2007):

$$
\delta_{\mathrm{b}}=2 \pi H_{\mathrm{sb}} / g T^{2},
$$

where $\delta_{\mathrm{b}}$ is the wave steepness calculated from the NDBC buoys; $H_{\mathrm{sb}}$ is the SWH (m) from the NDBC buoys; and $T$ is the period (s) of the wave spectral peak measured by the NDBC buoys.

The multilayer classifier perception includes two hidden layers. The transfer function of the hidden layer is a hyperbolic tangent sigmoid transfer function $f(x)=2 /[1+\exp (-2 x)]-1$ (Lin et al., 2006), and the transfer function of the output layer is a linear function $f(x)=x+b$ (Lin et al., 2006). The correlation coefficient $(r)$ between the buoy calculated $\delta_{\mathrm{b}}$ and those retrieved from the ERS-2 data was 0.80 , the root mean square was 0.0043 (Fig.2). The contour lines show the distribution of the data, which is concentrated near the diagonal line.

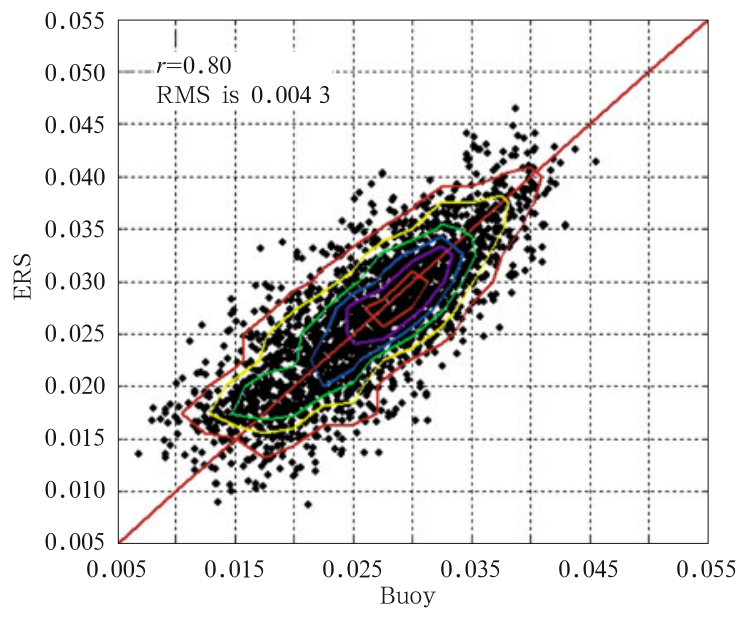

Fig.2. Comparison of $\delta$ between the buoy records and those retrieved from ERS-2 data.

Sea surface temperature (SST) data are needed when the $\mathrm{Sc}$ correction of the air-sea $\mathrm{CO}_{2}$ transfer velocity is calculated from the ERS-2 data. NOAA optimum interpolation (OI) SST V2 monthly mean of sea surface temperature is obtained from NCEP Climate Modeling Branch (http://www.es- rl.noaa.gov/psd/data/gridded/data.noaa.oisst. v2. html). The spatial coverage of the air temperature data is $1^{\circ}$ latitude by $1^{\circ}$ longitude, on a global grid $(360 \times 180), 89.5^{\circ} \mathrm{N}-89.5^{\circ} \mathrm{S}, 0.5^{\circ}-$ $359.5^{\circ} \mathrm{E}$. Temporal coverage is from December 1981 to August 2011.

The sea-air $\mathrm{CO}_{2}$ partial pressure $\left(p_{\mathrm{CO}_{2}}\right)$ difference data and the solubility of $\mathrm{CO}_{2}$ are needed when the global air-sea $\mathrm{CO}_{2}$ flux is estimated. The sea surface $p_{\mathrm{CO}_{2}}$ data and the solubility of $\mathrm{CO}_{2}$ over the global oceans are a climatologically mean under non El Niño conditions (Takahashi et al., 2010). These data have a spatial resolution of $4^{\circ}$ latitude by $5^{\circ}$ longitude for the reference year of 2000 and are based on about 4.75 million measurements of surface water $p_{\mathrm{CO}_{2}}$ and solubility of $\mathrm{CO}_{2}$ obtained from 1957 to 2009 by the Lamont-Doherty Earth Observatory 
database, which includes open ocean and coastal water measurements (Takahashi et al., 2010). The global $p_{\mathrm{CO}_{2}}$ and solubility of $\mathrm{CO}_{2}$ data are available free of charge as a numeric data package from the carbon dioxide Information Analysis Center (CDIAC) (http://cdiac.ornl.gov/ftp/ oceans/ LDEO_Database/ Version_ 2009/).

The GASEX-98 data are obtained from the Gas Ex 98 cruise (http://www.aoml.noaa.gov/ocd/gcc/gasex98/). The Gas Ex 98 cruise was conducted in the north Atlantic and northeast Pacific Oceans between May 7, 1998, and July 27, 1998. The primary focus of the cruise was a 1month process study in which an open-ocean air-sea exchange experiment was conducted within a cold-core eddy. The name "ASGAMAGE" is a contraction of ASGAS-EX (for air sea gas exchange, an earlier project with partially the same participants) and MAGE (for marine aerosol and gas exchange), activity 1.2. of IGAC, the international global atmospheric chemistry project, which in turn is part of the IGBP programme. The ASGAMAGE data are from that.

The area weighted global $\mathrm{CO}_{2}$ transfer velocity and flux were calculated on a $2^{\circ} \times 2^{\circ}$ grid and the transfer velocity was corrected for $S c$ using the formula from Wanninkhof (1992).

The method and data introduced above are shown in Fig.3.

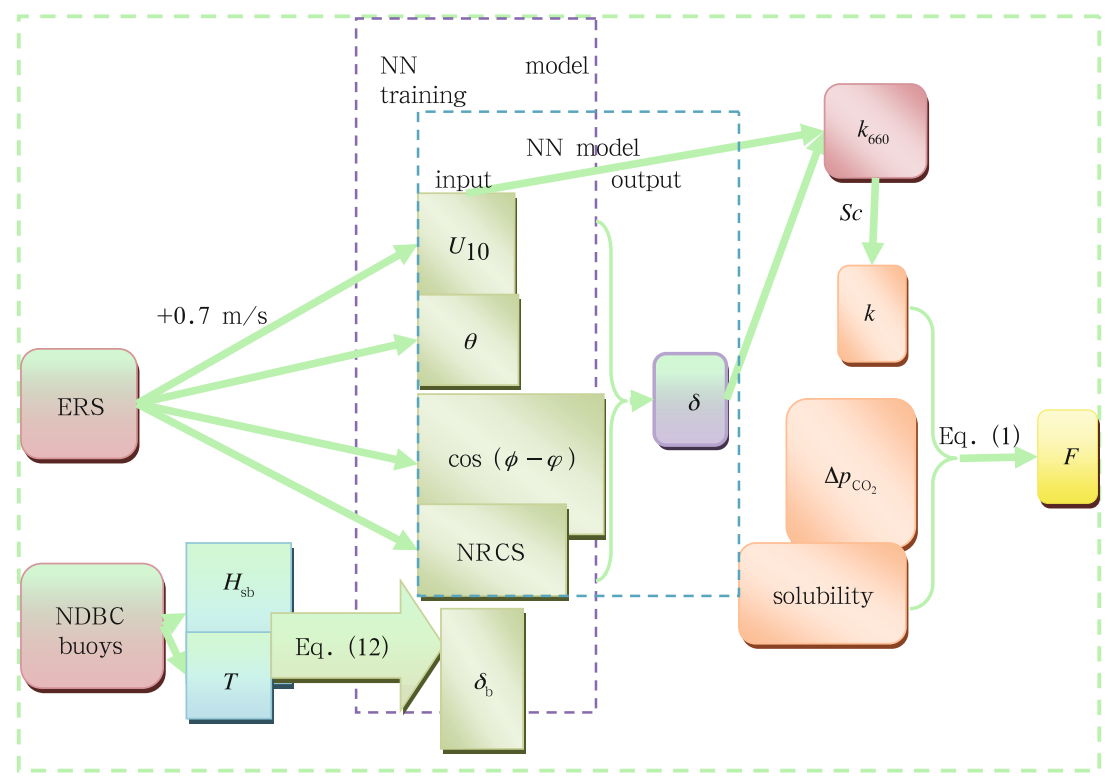

Fig.3. Flow chart of the method.

\section{Results and discussion}

\subsection{Comparison of the new formula with the former ones}

Equation (8) shows that the gas transfer velocity is proportional to the wind speed and is inversely proportional to the wave steepness. For a given wind speed, the gas transfer velocity decreases with the wave steepness. It is quantitatively consistent with various existing models. The wave steepness must be adjusted and a specific value of the wave steepness must be chosen for exact comparisons with other studies. Thus, Eq. (8) can be an effectual method to calculate the effects of waves on determining of air-sea gas fluxes.

Figure 4 shows the comparison of gas transfer velocities at various wave steepness values with some existing wind speed parameterizations. The yellow points are the air-sea $\mathrm{CO}_{2}$ transfer velocity computed from the ERS-2 data using the method introduced above. Some observational data are also plotted in the figure. The contour lines show that the distribution of the ERS-2 retrieved transfer velocity is concentrated between wind speeds of 4 and $15 \mathrm{~m} / \mathrm{s}$. That is because the wind speeds are more common in that range. The wind speed in our figure is up to $20 \mathrm{~m} / \mathrm{s}$ because it is widely believed that the data are not accurate when the wind speed higher than $20 \mathrm{~m} / \mathrm{s}$ retrieved by the ERS data and it is common for wind lower than $20 \mathrm{~m} / \mathrm{s}$. The validity of Eq. (8), when the wind speed is higher than $20 \mathrm{~m} / \mathrm{s}$, awaits further observation data in the future work.

It is evident that the gas transfer velocities calculated by

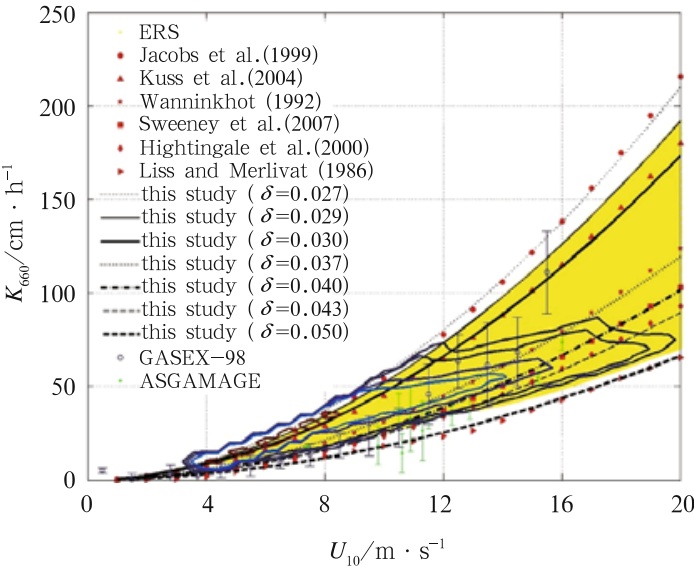

Fig.4. Comparisons of gas transfer velocity of Eq. (8) at wave steepness values of $0.027,0.030,0.037,0.040,0.043$ and 0.050 with other wind speed parameterizations. The ERS-2 retrieved transfer velocity (the yellow points) and some observational data are also plotted in the figure. The contour lines show the distribution of the ERS-2 retrieved transfer velocity.

Eq. (8), at the wave steepness values of $0.027,0.030,0.037$, $0.040,0.043$ and 0.050 are consistent with those calculated using the relationships proposed by Jacobs et al. (1999), Kuss et al. (2004), Wanninkhof (1992), Sweeney et al. (2007), Nightingale 
et al. (2000) and Liss and Merlivat (1986), respectively. Such consistency has been previously discussed in detail (Zhao and Xie, 2010). The low limit of the wave steepness is 0.029 , corresponds to a fully developed wave field. Another reason why we set the low limit of the wave steepness is that a small error of the wave steepness can cause a large error of the transfer velocity especially when the value of the wave steepness is small. And the high limit of the wave steepness is $1 / 15$, and this is a universal, physical limitation in deep water, imposed by wave breaking (Holthuijsen, 2007). Because both Eq. (5) and Eq. (7)

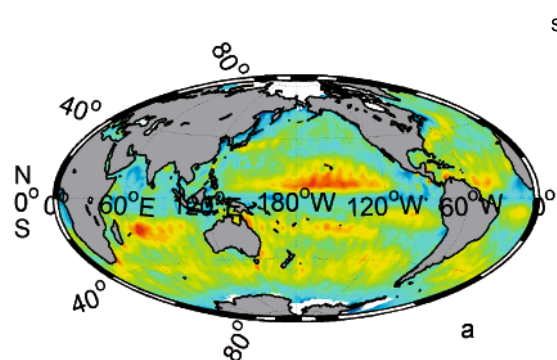

spring
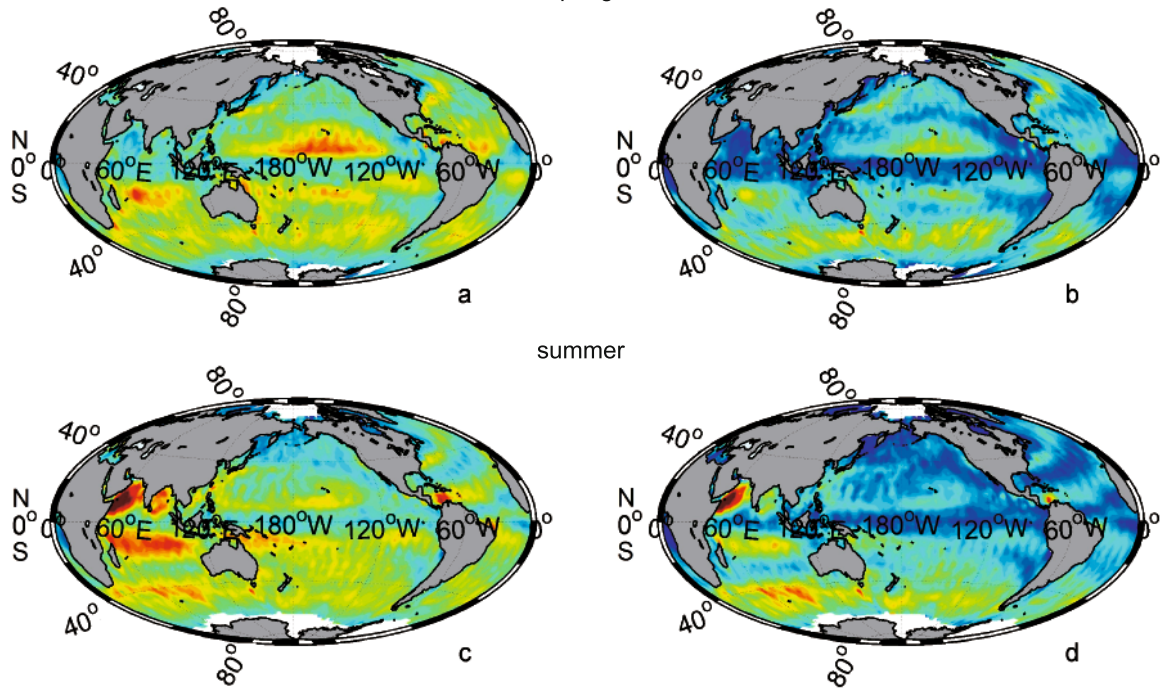

summer
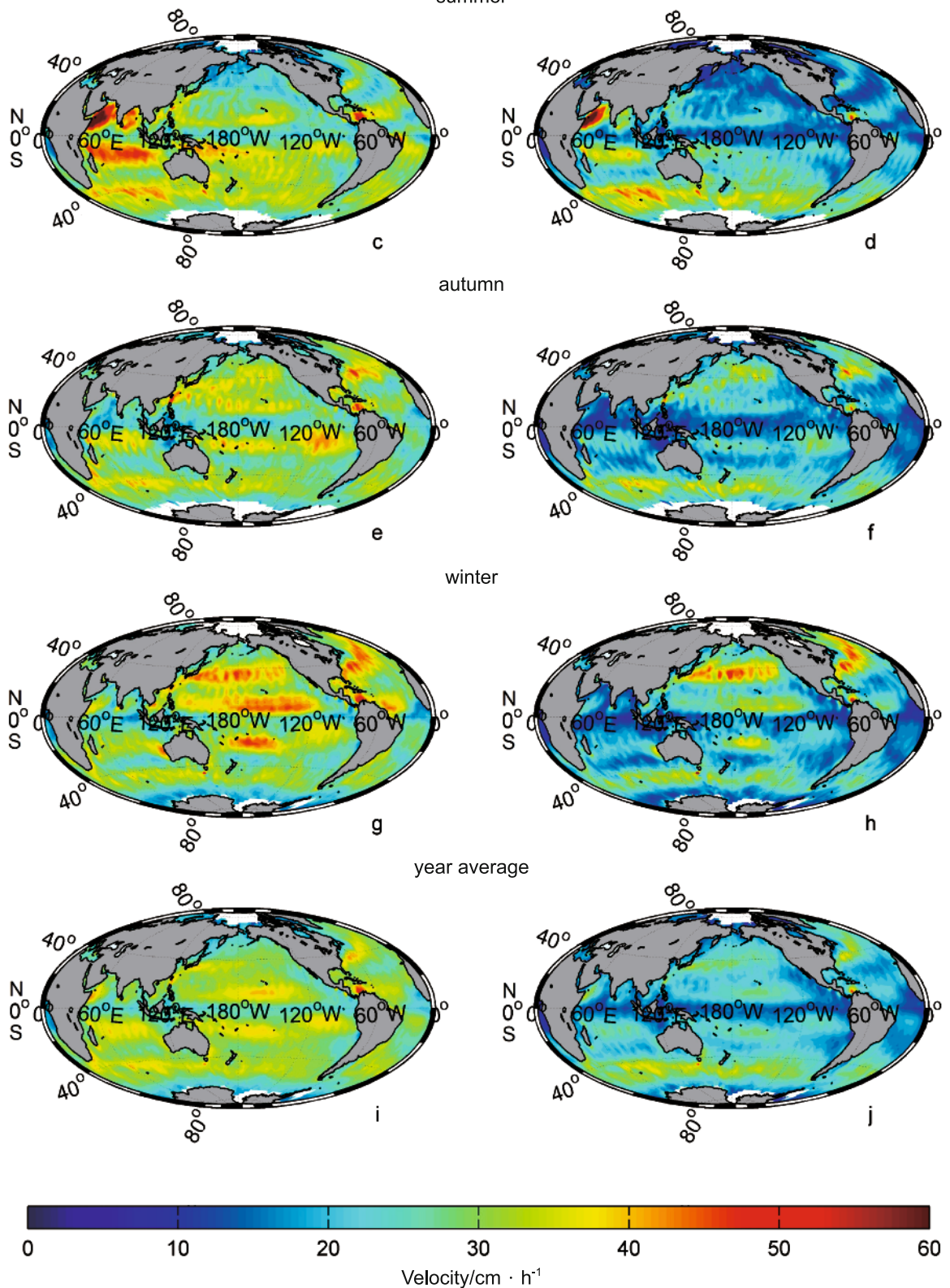

Fig.5. Average air-sea $\mathrm{CO}_{2}$ transfer velocity. The left panel is from this paper and the right panel is from Wanninkhof (1992). 


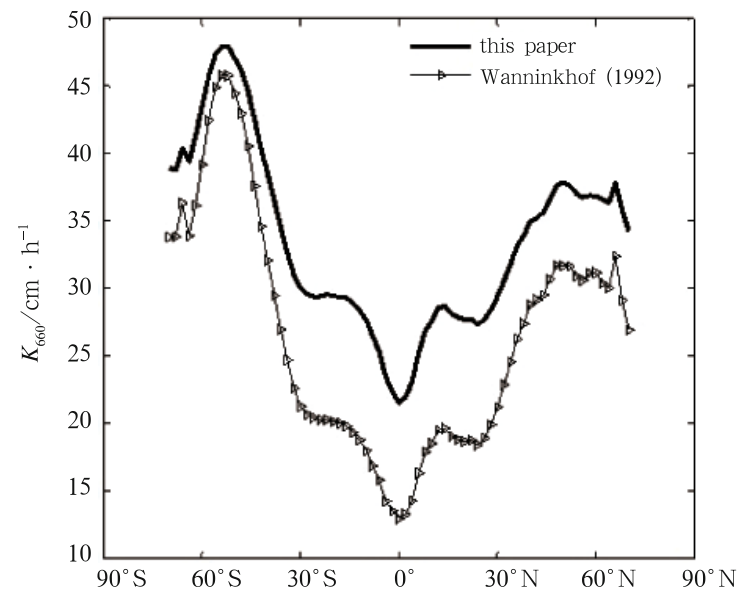

Fig.6. Latitudinal distribution of air-sea $\mathrm{CO}_{2}$ transfer velocity.

are obtained from an empirical relationship, the proportionality factor in Eq. (8) is highly uncertain. For Eq. (7) the proportionality factor can vary from 0.0268 to 0.0310 (Toba, 1972; Wang, 1990; Guan and Sun, 2002). For Eq. (5), the possible range of the factor is unknown because the unavailable data used by Zhao and Xie (2010). This work will be done in the future work with further data.

The use of the NN method to retrieve the wave steepness also reduces the precision of the calculated transfer velocity. There are relatively few transfer velocity data retrieved from ERS-2 with a wave steepness larger than 0.043 . This lack of measurements above 0.045 is a limiting factor in the use of the $\mathrm{NN}$ model as shown in Fig.2.

\subsection{Global air-sea $\mathrm{CO}_{2}$ transfer velocity}

The global distribution of the transfer velocities is shown in Fig.5. The latitudinal distribution of the air-sea $\mathrm{CO}_{2}$ transfer velocity is shown in Fig.6. The global area-weighted Schmidt number corrected mean gas transfer velocity is $30 \mathrm{~cm} / \mathrm{h}$. This compares with $22 \mathrm{~cm} / \mathrm{h}$ obtained using the formula given by Wanninkhof (1992). The uncertainty still remains with the in situ data.

The highest transfer velocities are found around $60^{\circ} \mathrm{N}$ and $60^{\circ} \mathrm{S}$. In the north Pacific Ocean, there are the high transfer velocities near the Kuroshio Current and the north Pacific Current. The currents enhance the air-sea interface mixing causing the transfer velocities to increase (Smith, 1999). Also, because of the enhanced turbulence and energy dissipation at ocean fronts (D'Asaro et al., 2011), there are the high transfer velocities near the polar front. Based on the same reason, there are the high transfer velocities near the Azores Current and the Azores front. In the Southern Ocean, because of the strong westerly wind, the Antarctic Circumpolar Current and the attendance of the subantarctic front, there is the highest transfer velocity here, especially in the southern Indian Ocean. The lowest values are found on the equator, because of the low wind speeds there. The distribution of transfer velocities across both hemispheres is similar.

In spring and winter, the transfer velocity at around latitude $15^{\circ}$ in both hemispheres is higher than that in summer and autumn. It may be affected by the seasonal variation of the trade-wind belt (Fig. 7, left panel). In summer, there is a significantly high transfer velocity in the northwest Indian Ocean near the Gulf of Aden, especially in June. This is thought to be because there is a strong convection around the Red Sea, the Gulf of Aden and the Arabian Sea. It is seasonal and depends on the appearance of monsoons. In winter, there is a high transfer velocity near $40^{\circ} \mathrm{N}$ and it is believed that this may be due to the effect of the seasonally strong Kuroshio Current and the Gulf Stream (Smith, 1999).

Similar patterns were reported in the result calculated using the formula given by Wanninkhof (1992). However, although sharing a similar pattern, the transfer velocities reported from our work have less contrast. The gas transfer velocities calculated by our algorithm are higher than those by using Wanninkhof (1992) algorithm, especially on the equator. This is because most of the wave steepness is lower than the value corresponding to Wanninkhof (1992) in Fig.4 (0.037). And the equator has the lowest value of the wave steepness (Fig. 7).

\subsection{Global air-sea $\mathrm{CO}_{2}$ flux}

The global distribution of the $\mathrm{CO}_{2}$ flux is shown in Fig.8. The latitudinal distribution of the air-sea $\mathrm{CO}_{2}$ flux is shown in Fig.9. The global area-weighted Schmidt number corrected mean $\mathrm{CO}_{2}$ flux (calculated by carbon) is $-1.77 \mathrm{Pg} / \mathrm{a}$, compared with $-1.79 \mathrm{Pg} / \mathrm{a}$ using the formula given by Wanninkhof (1992). The negative value means that the $\mathrm{CO}_{2}$ flux is from the atmosphere into the ocean, while a positive value indicates a flux from the ocean into the atmosphere. Both of these values are similar with the yielded global uptake flux of anthropogenic carbon of 1.95 Pg/a for the year 1995 (Gerber et al., 2009), the estimated total ocean uptake flux including the anthropogenic $\mathrm{CO}_{2}$ (calculated by carbon) of $(-2.0 \pm 1.0) \mathrm{Pg} / \mathrm{a}$ in 2000 (Takahashi et al., 2009), and the ocean absorbed approximately $2 \mathrm{Pg} / \mathrm{a}$ in the past two decades (Lohrenz, 2010). Compared with Table 1 and Table 2 in $\mathrm{Hu}$ and Guan (2008), our value is reasonable. There are different reasons for the magnitude of the air-sea $\mathrm{CO}_{2}$ flux such as different transfer velocities and different wind speed data and other data.

The highest air-sea $\mathrm{CO}_{2}$ flux is apparent in the area near the North Pole, about $68^{\circ} \mathrm{N}$. This is because the transfer velocities are high there. The high values apparent at around $40^{\circ} \mathrm{N}$ and $40^{\circ} \mathrm{S}$, as well as at around $75^{\circ} \mathrm{N}$ and $75^{\circ} \mathrm{S}$ are because the air-sea $\mathrm{CO}_{2}$ partial pressure differences are high there. This is a good example because the transfer velocities there are not such remarkable. The sea to air $\mathrm{CO}_{2}$ flux is the strongest in the equatorial east Pacific Ocean because the sea-air $\mathrm{CO}_{2}$ partial pressure difference is the largest in the oceans, even though the transfer velocity there is the lowest. The air to sea $\mathrm{CO}_{2}$ flux is significantly strong both in the north Pacific and Atlantic Oceans. The Labrador Sea is the strongest $\mathrm{CO}_{2}$ sink. This is because the airsea $\mathrm{CO}_{2}$ transfer velocity is high there especially in spring and winter. The average air-sea $\mathrm{CO}_{2}$ flux in the Antarctic Circumpolar Current is also high, especially in summer, again due to the high transfer velocities there. There is also a high air-sea $\mathrm{CO}_{2}$ flux in the southwest Atlantic Ocean, especially in winter, which is due to the high air-sea $\mathrm{CO}_{2}$ partial pressure difference.

In summer, there is a strong source of $\mathrm{CO}_{2}$ in the northwest India Ocean near the Gulf of Aden. That is because the transfer velocity and the air-sea $\mathrm{CO}_{2}$ partial pressure difference are both high. It also depends on the season and the appearance of monsoons. We also have found that the circum-Antarctic seas are strong sources of $\mathrm{CO}_{2}$ during summer and autumn. There is also strong $\mathrm{CO}_{2}$ source in the Bering Sea in spring and winter that is because the air-sea $\mathrm{CO}_{2}$ partial pressure difference is a little high there in these seasons. 
The above phenomenon is consistent with the results using the formula given by Wanninkhof (1992). However, there is still some difference in it. Though it seems there is no noticeable difference in the global distributions of gas flux shown in Fig. 9, it has the same phenomenon as that of the transfer ve- locity in Fig. 6. For example, there are larger sources and sinks of $\mathrm{CO}_{2}$ calculated using our transfer velocity than those of Wanninkhof (1992), especially on the equator, just the same as the transfer velocity. Maybe it seems not so noticeable because the value and the axis are relatively not so noticeable.
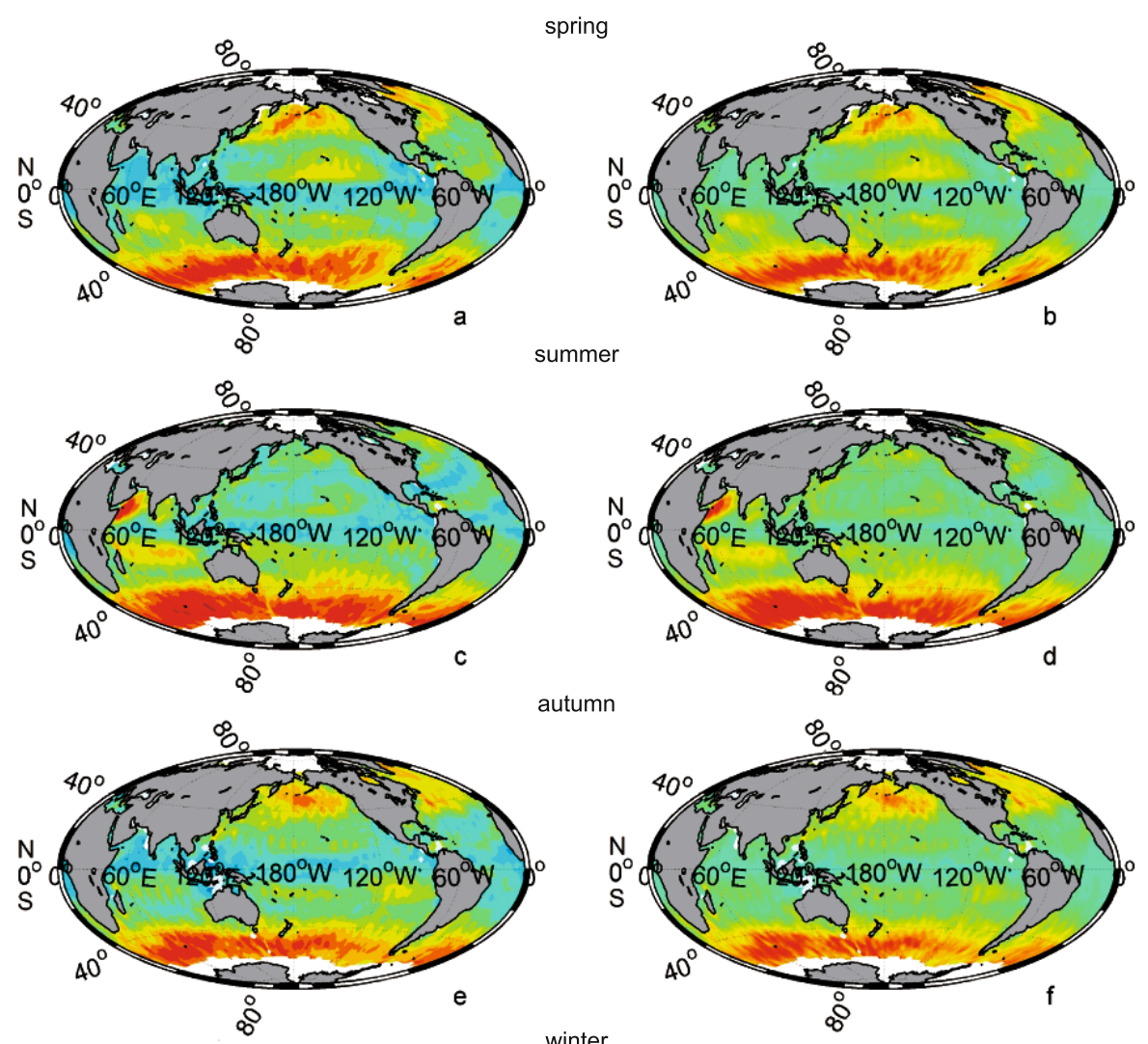

autumn
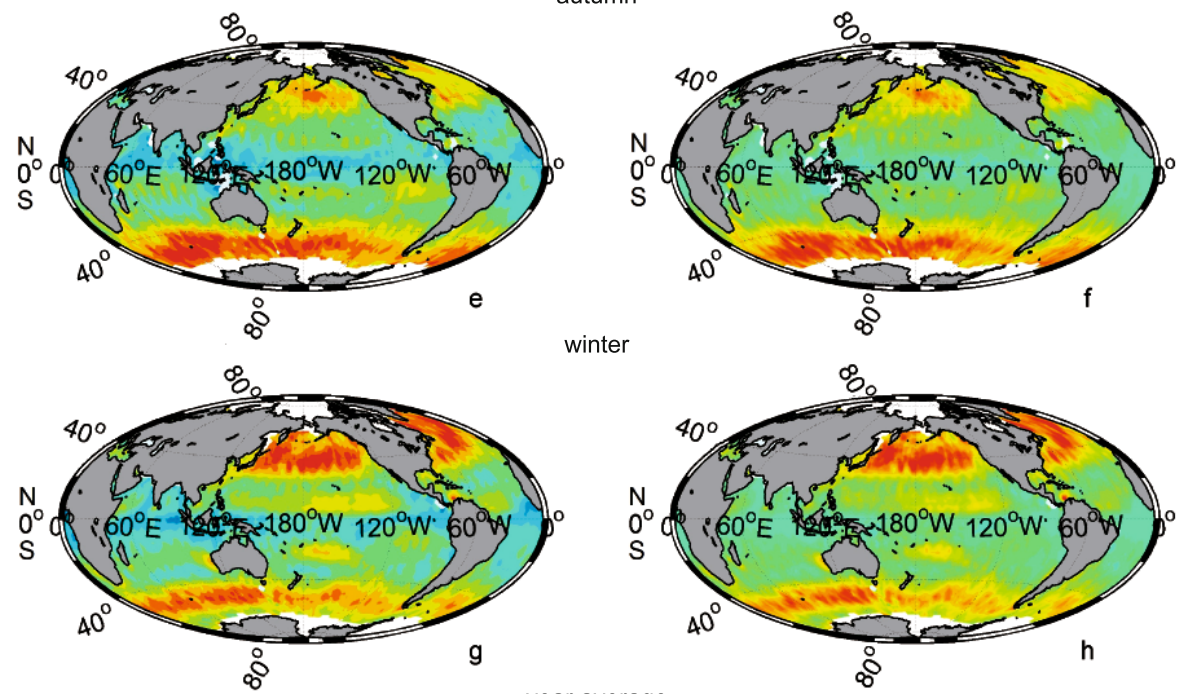

winter
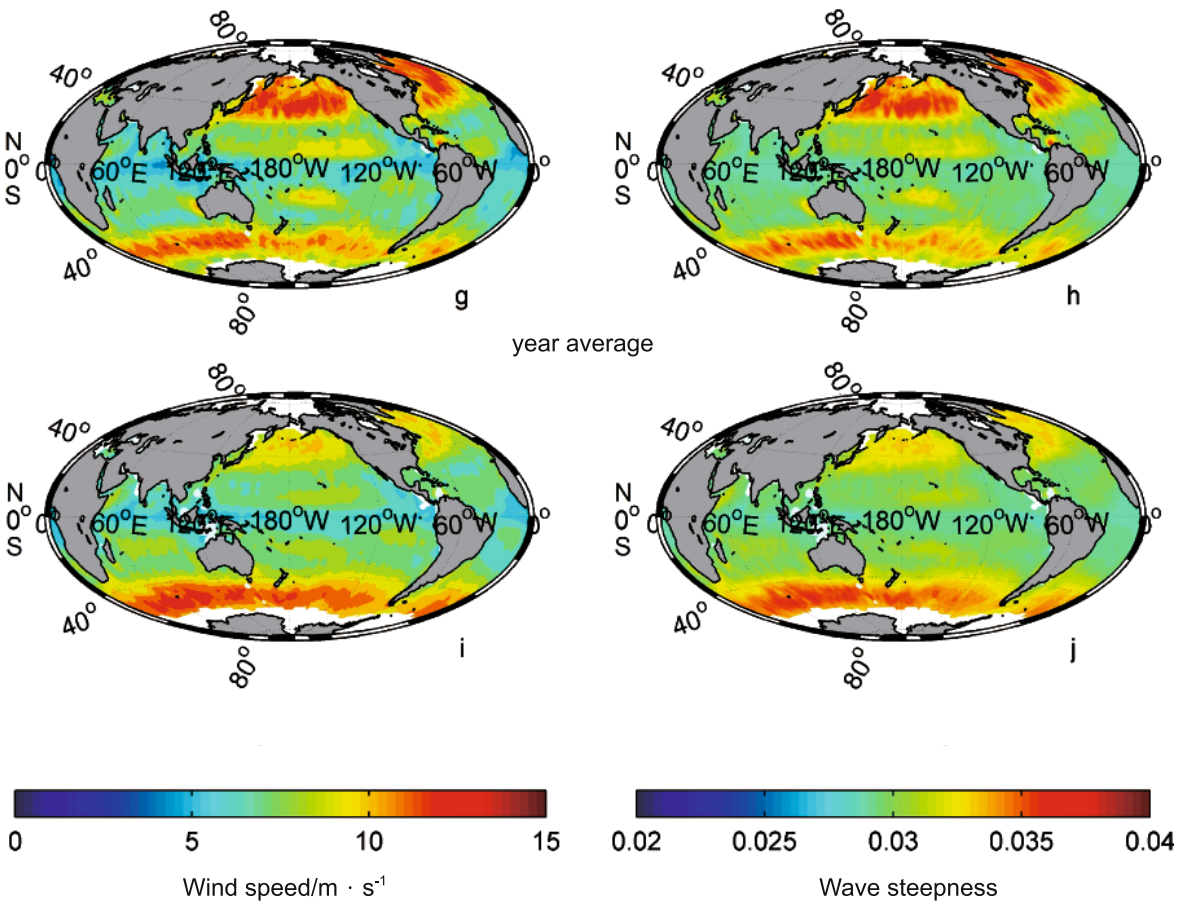

Fig.7. Distribution of wind speed (left panel) and wave steepness (right panel). 

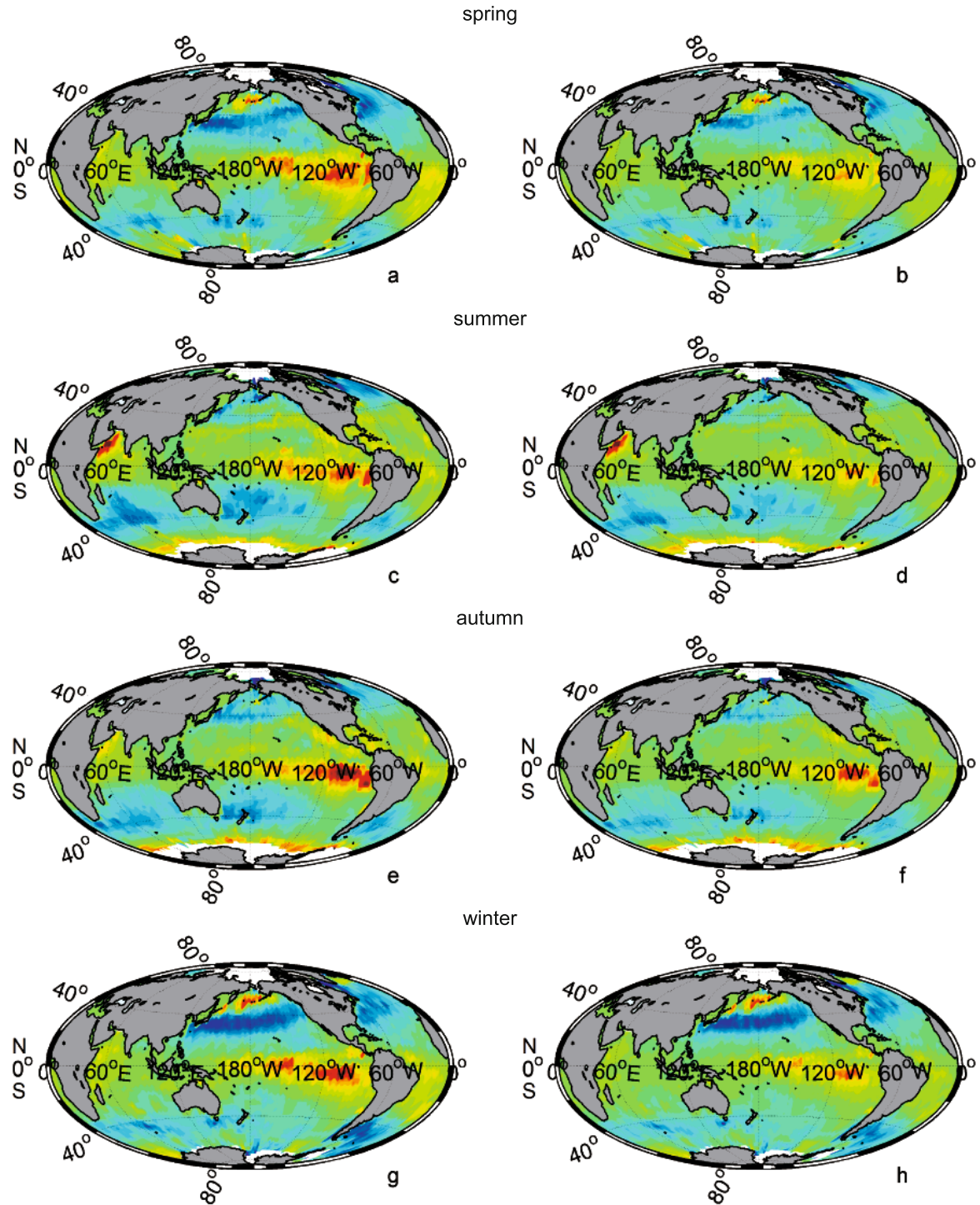

unter
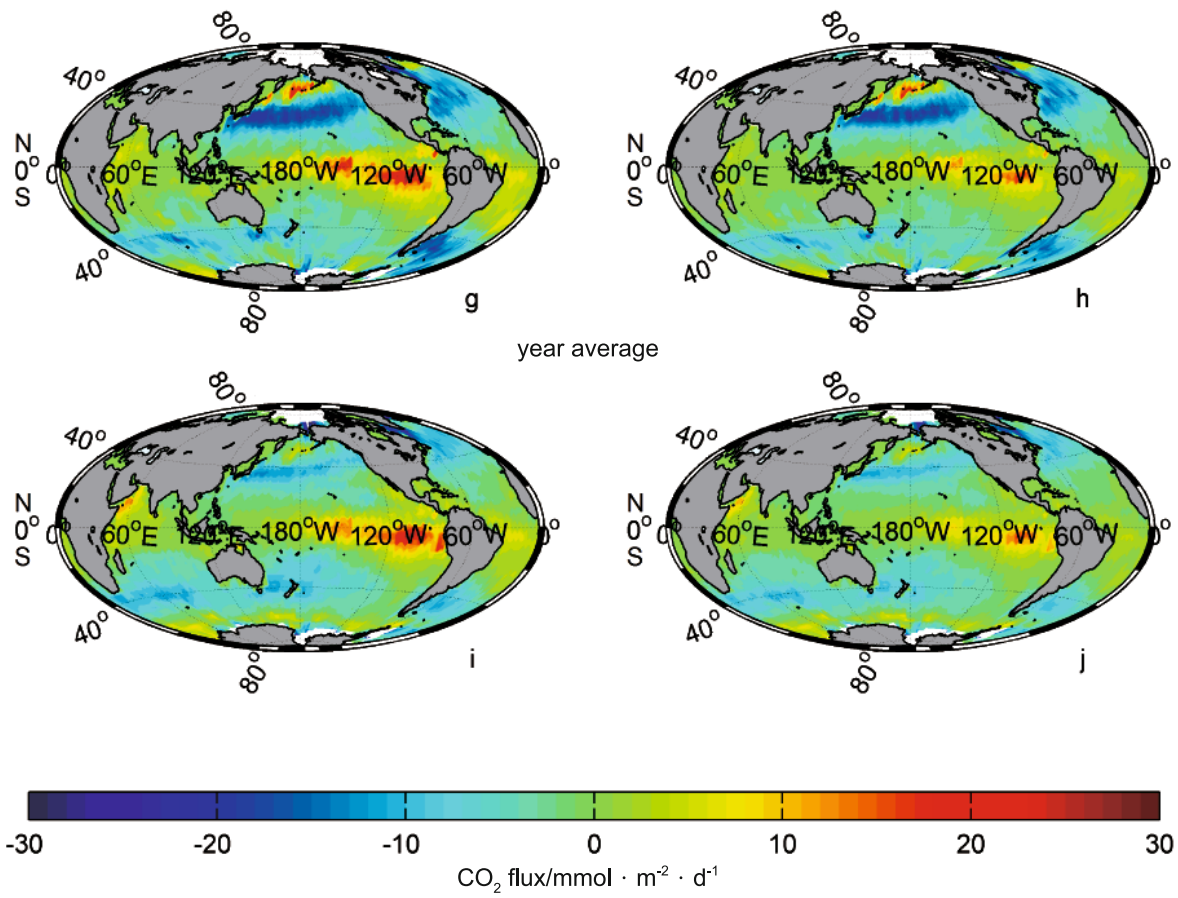

Fig.8. Average air-sea $\mathrm{CO}_{2}$ flux. The left panel is from this paper and the right panel is from Wanninkhof (1992).

\section{Conclusions}

We have presented an algorithm to retrieve air-sea $\mathrm{CO}_{2}$ transfer velocities from ERS-2 scatterometer data based on the algorithm proposed by Zhao and Xie (2010). In this study, we have considered the influence of wave steepness on gas transfer velocities and flux. 
The gas transfer velocity is proportional to the wind speed and is inversely proportional to the wave steepness. It is a little more sensitive to the wave steepness than to the wind speed and it is quantitatively consistent with various existing parameterizations.

The global area-weighted Schmidt number corrected mean gas transfer velocity is $30 \mathrm{~cm} / \mathrm{h}$, compared with $22 \mathrm{~cm} / \mathrm{h}$ using the formula given by Wanninkhof (1992). The highest transfer velocity occurs around $60^{\circ} \mathrm{N}$ and $60^{\circ} \mathrm{S}$, while the lowest on the equator. In this study, a new algorithm including the wave steepness and the wind speed is presented. Our model can be used almost in the whole wave state and is closer to the true process of the air-sea gas exchange.

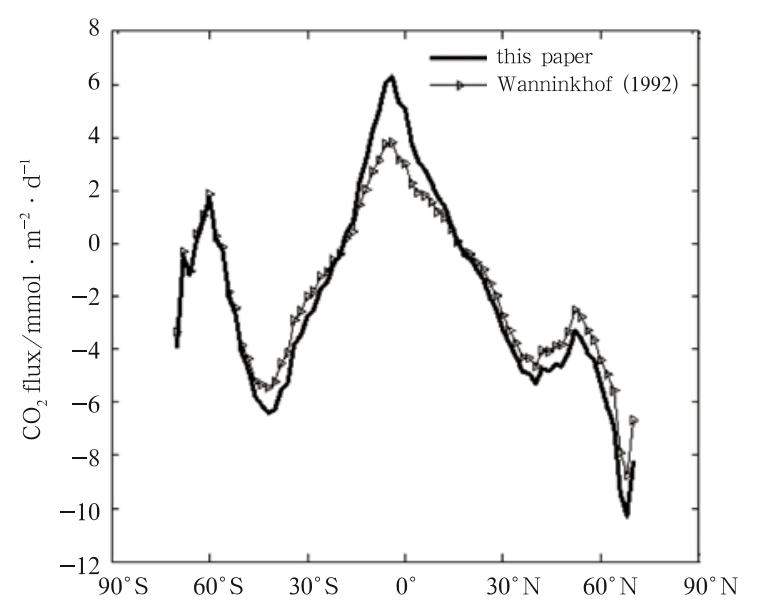

Fig.9. Latitudinal distribution of air-sea $\mathrm{CO}_{2}$ flux.

The global area-weighted Schmidt number corrected mean $\mathrm{CO}_{2}$ flux (calculated by carbon) is $-1.77 \mathrm{Pg} / \mathrm{a}$, compared with $-1.79 \mathrm{Pg} / \mathrm{a}$ using the formula given by Wanninkhof (1992). The highest air-sea $\mathrm{CO}_{2}$ flux is apparent in the $68^{\circ} \mathrm{N}$. And the high values are apparent at around $40^{\circ} \mathrm{N}$ and $40^{\circ} \mathrm{S}$, as well as at around $75^{\circ} \mathrm{N}$ and $75^{\circ} \mathrm{S}$. The sea to air $\mathrm{CO}_{2}$ flux is the strongest in the equatorial east Pacific Ocean. The phenomenon is consistent with the results using the formula given by Wanninkhof (1992) though our values are a little higher especially in equatorial areas.

The uncertainty and error caused using an NN model can be reduced but more data are needed.

\section{Acknowledgements}

The authors are grateful to Wanninkhof Rik from the National Oceanographic and Atmospheric Administration/Atlantic Oceanographic and Meteorological Laboratory for his valuable help. The authors are also grateful to Pan Delu from the Second Institute of Oceanography, the State Oceanic Administration, Zhao Dongliang from the Physical Oceanography Laboratory, Ocean University of China and Ding Yongyao from the First Institute of Oceanography, the State Oceanic Administration for their helpful discussion.

\section{References}

Bock E J, Hara T, Frew N M, et al. 1999. Relationship between airsea gas transfer and short wind waves. Journal of Geophysical Research-Oceans, 104(C11): 25821-25831

Bogucki D, Carr M E, Drennan W M, et al. 2010. Preliminary and nove estimates of $\mathrm{CO}_{2}$ gas transfer using a satellite scatterometer during the 2001GasEx experiment. International Journal of Remote Sensing, 31(1): 75-92, doi: 10.1080/01431160902882546
Carter D J T. 1982. Prediction of wave height and period for a constant wind velocity using the JONSWAP results. Ocean Engineering, 9(1): 17-33

D’Asaro E, Lee C, Rainville L, et al. 2011. Enhanced turbulence and energy dissipation at ocean fronts. Science, 332(6027): 318-322

Denman K L, Brasseur G, Chidthaisong A, et al. 2007. Couplings between changes in the climate system and biogeochemistry. In: Solomon S, Qin D, Manning M, et al., eds. Climate Change 2007: The Physical Science Basis. Contribution of Working Group I to the Fourth Assessment Report of the Intergovernmental Panel on Climate Change. Cambridge, United Kingdom and New York, NY, USA: Cambridge University Press, 499-587

Fairaill C W, Hare J E, Edson J B, et al. 2000. Parameterization and micrometeorological measurement of air-sea gas transfer. Boundary-Layer Meteorology, 96(1): 63-106, doi: 10.1023/ a: 1002662826020

Frankignoulle M. 1988. Field-measurements of air sea $\mathrm{CO}_{2}$ exchange. Limnology and Oceanography, 33(3): 313-322

Frew N M, Bock E J, Schimpf U, et al. 2004. Air-sea gas transfer: Its dependence on wind stress, small-scale roughness, and surface films. Journal of Geophysical Research-Oceans, 109: C08S17, doi: 10.1029/2003JC002131

Frew N M, Glover D M, Bock E J, et al. 2007. A new approach to estimation of global air-sea gas transfer velocity fields using dual-frequency altimeter backscatter. Journal of Geophysical Research-Oceans, 112: C11003, doi: 10.1029/2006JC003819

Gerber M, Joos F, Vazquez-Rodriguez M, et al. 2009. Regional airsea fluxes of anthropogenic carbon inferred with an ensemble Kalman Filter. Global Biogeochemical Cycles, 23: GB1013, doi: 10.1029/2008GB003247

Glover D M, Frew N M, Mccue S J. 2007. Air-sea gas transfer velocity estimates from the Jason-1 and TOPEX altimeters: prospects for a long-term global time series. Journal of Marine Systems, 66: 173-181, doi: 10.1016/j.jmarsys.2006.03.020

Guan Changlong, Sun Qun. 2002. Analytically derived wind wave growth relations. China Ocean Engineering, 16(3): 359-368

Holthuijsen L H. 2007. Waves in Oceanic and Coastal Waters. Cambridge, United Kingdom and New York, NY, USA: Cambridge University Press

$\mathrm{Hu}$ Wei, Guan Changlong. 2008. Estimate of global sea-air $\mathrm{CO}_{2}$ flux with sea-state-dependent parameterization. Journal of Ocean University of China, 7(3): 237-240

Jacobs C M J, Kohsiek W, Oost W A. 1999. Air-sea fluxes and transfer velocity of $\mathrm{CO}_{2}$ over the North Sea: results from ASGAMAGE. Tellus Series B-Chemical and Physical Meteorology, 51(3): 629641

Jähne B, Münnich K O, Böslnger R, et al. 1987. On the parameter$\mathrm{s}$ influencing air-water gas exchange. Journal of Geophysical Research-Oceans, 92(C2): 1937-1949

Keeling C D, Whorf T P, Wahlen M, et al. 1995. Interannual extremes in the rate of rise of atmospheric carbon-dioxide since 1980. Nature, 375(6533): 666-670

Kuss J, Nagel K, Schneider B. 2004. Evidence from the Baltic Sea for an enhanced $\mathrm{CO}_{2}$ air-sea transfer velocity. Tellus Series B-Chemical and Physical Meteorology, 56(2): 175-182

Lin Mingsen, Song Xingai, Jiang Xingwei. 2006. Neural network wind retrieval from ERS-1/2 scatterometer data. Acta Oceanologica Sinica, 25(3): 35-39

Liss P S, Merlivat L. 1986. Air-sea gas exchange: rate introduction and synthesis. In: Buat-Ménard P, ed. The Role of Air-Sea Exchange in Geochemical Cycling. Dordrecht, Holland: D Reidel Publishing Company, 113-127

Liu Guoqiang, He Yijun, Shen Hui, et al. 2011. Global drag-coefficient estimates from scatterometer wind and wave steepness. IEEE Transactions on Geoscience and Remote Sensing, 49(5): 14991503

Lohrenz S E C, Cai Wei-Jun, Chen Feizhou, et al. 2010. Seasonal variability in air-sea fluxes of $\mathrm{CO}_{2}$ in a river-influenced coastal margin. Journal of Geophysical Research, 115(C10): C10034

McGillis W R, Edson J B, Hare J E, et al. 2001a. Direct covariance air-sea $\mathrm{CO}_{2}$ fluxes. Journal of Geophysical Research-Oceans, 106(C8): 16729-16745 
McGillis W R, Edson J B, Ware J D, et al. 2001b. Carbon dioxide flux techniques performed during GasEx-98. Marine Chemistry, 75(4): 267-280

Miller S D, Marandino C, Saltzman E S. 2010. Ship-based measurement of air-sea $\mathrm{CO}_{2}$ exchange by eddy covariance. Journal of Geophysical Research-Atmospheres, 115: D02304

Nightingale P D, Liss P, Schlosser P. 2000. Measurements of air-sea gas transfer during an open ocean algal bloom. Geophysical Research Letters, 27(14): 2117-2120

Perrie W, Zhang Weiqing, Ren Xuejuan, et al. 2004. The role of midlatitude storms on air-sea exchange of $\mathrm{CO}_{2}$. Geophysical Research Letters, 31: L09306

Portabella M, Stoffelen A. 2007. Development of a global scatterometer validation and monitoring. Ocean and Sea Ice SAF, Scientific Report for SAF/OSI/CDOP/KNMI/SCI/RP/141: 1-37, http://www.knmi.nl/publications/fulltexts/wind_stress_osi_ saf_final_report_copyl.pdf/2012-10-08

Portabella M, Stoffelen A. 2009. On scatterometer ocean stress. Journal of Atmospheric and Oceanic Technology, 26(2): 368-382

Prytherch J, Yelland M J, Pascal R W, et al. 2010. Direct measurements of the $\mathrm{CO}_{2}$ flux over the ocean: development of a novel method. Geophysical Research Letters, 37: L03607

Sabine C L, Feely R A, Gruber N, et al. 2004. The oceanic sink for anthropogenic $\mathrm{CO}_{2}$. Science, 305(5682): 367-371

Sarmiento J L, Monfray P, Maier-Reimer E, et al. 2000. Sea-air $\mathrm{CO}_{2}$ fluxes and carbon transport: a comparison of three ocean general circulation models. Global Biogeochemical Cycles, 14(4): 1267-1281

Smith J. 1999. Wave breaking on an opposing current. Coastal Engineering Technical Note CETN IV-17, US Army Engineer Research and Development Centre, Vicksburg MS, http://cirpteam. wes.army.mil/pubs/chetns/CETN-IV-17.pdf/2012-04-06
Sweeney C, Gloor E, Jacobson A R, et al. 2007. Constraining global airsea gas exchange for $\mathrm{CO}_{2}$ with recent bomb ${ }^{14} \mathrm{C}$ measurements. Global Biogeochemical Cycles, 21: GB2015

Takahashi T, Sutherland S C, Kozyr A. 2010. Global ocean surface water partial pressure of $\mathrm{CO}_{2}$ database: measurements performed during 1957-2009 (Version 2009). Oak Ridge, Tennessee: Carbon Dioxide Information Analysis Center, Oak Ridge National Laboratory, U S Department of Energy

Takahashi T, Sutherland S C, Wanninkhof R, et al. 2009. Climatological mean and decadal change in surface ocean $p_{\mathrm{CO}_{2}}$, and net seaair $\mathrm{CO}_{2}$ flux over the global oceans. Deep-Sea Research (Part II): Topical Studies in Oceanography, 56 (8-10): 554-577

Toba Y. 1972. Local balance in the air-sea boundary processes: I. On the growth process of wind waves. Journal of the Oceanographical Society of Japan, 28: 109-121

Wang Bingxiang. 1990. An investigation on the $\delta-\beta$ relationship of ocean waves. J Ocean Univ Qingdao (in Chinese), 20(3): 1-9

Wanninkhof R. 1992. Relationship between wind-speed and gasexchange over the ocean. Journal of Geophysical ResearchOceans, 97(C5): 7373-7382

Wanninkhof R, Asher W E, Ho D T, et al. 2009. Advances in quantifying air-sea gas exchange and environmental forcing. Annual Review of Marine Science, 1: 213-244

Woolf D K. 2005. Parametrization of gas transfer velocities and seastate-dependent wave breaking. Tellus Series B-Chemical and Physical Meteorology, 57(2): 87-94

Zhao Dongliang, Toba Y, Suzuki Y, et al. 2003. Effect of wind waves on air-sea gas exchange: proposal of an overall $\mathrm{CO}_{2}$ transfer velocity formula as a function of breaking-wave parameter. Tellus Series B-Chemical and Physical Meteorology, 55(2): 478-487

Zhao Dongliang, Xie Lian. 2010. A practical bi-parameter formula of gas transfer velocity depending on wave states. Journal of Oceanography, 66: 663-671 